\title{
Thoratec implantable ventricular assist device: The Papworth experience
}

\author{
Marius Berman, MD, Jayan Parameshwar, MD, FRCP, David P. Jenkins, MS, FRCS, Kumud Dhital, PhD, \\ FRCS, Clive Lewis, PhD, FRCP, Kirsty Dempster, Paul Lincoln, Catherine Sudarshan, MD, FRCS, \\ Stephen R. Large, FRCP, FRCS, John Dunning, FRCS, and Steven S. L. Tsui, MD, FRCS
}

\begin{abstract}
Objective: The Thoratec (Thoratec Corp, Pleasanton, Calif) implantable ventricular assist device (IVAD) can be used for univentricular or biventricular support. The objective of this study is to review the 5-year experience of bridging patients to heart transplantation with this device in a single center. Surgical aspects, including hybrid pump pocket, double tunneling of driveline, and optimal cannulae placement, are discussed.
\end{abstract}

\begin{abstract}
Methods: This is a retrospective review of 24 patients treated between January 2002 and December 2007. Nineteen patients $(79.1 \%)$ received a single implantable ventricular assist device as left ventricular assist devices, and 5 patients $(21.9 \%)$ received 2 implantable ventricular assist devices as biventricular assist devices. The devices were implanted in pre-peritoneal/posterior rectus hybrid pump pockets. The driveline was passed through a 2-stage double-tunnel to exit onto the lateral chest wall. Patients were anticoagulated with Warfarin aiming for an international normalized ratio of 2.0 to 3.0.
\end{abstract}

Results: Twenty male and 4 female patients with a mean age of 39.8 years (17-57 years) and a body surface area of $1.87 \mathrm{~m}^{2}\left(1.63-2.2 \mathrm{~m}^{2}\right)$ were supported for a total of 2308 patient-days. Mean duration of support was 96 days (10-301 days). The cause of heart failure was dilated cardiomyopathy in 18 patients and ischemic cardiomyopathy in 6 patients. Preoperatively, 23 patients were receiving inotropes, 12 patients required intra-aortic balloon pump support, 5 patients were intubated and mechanically ventilated, and 3 patients required continuous venovenous hemofiltration for renal support. Eleven patients $(45.8 \%)$ were discharged with ventricular assist device support (1015 home patient-days). Complications observed were a) neurologic: stroke in 3 patients, transient ischemic attacks in 4 patients; and b) infection: driveline infection in 3 patients and pump pocket infection in 1 patient. There was no mechanical device failure. Support to transplantation was achieved in 17 patients (70.8\%): 3 of 5 biventricular assist devices (60\%) and 14 of 19 left ventricular assist devices $(73.7 \%)$.

Conclusion: The Thoratec IVAD is a versatile and reliable ventricular assist device. It can provide univentricular or biventricular support for bridging patients to heart transplantation with acceptable complication rates. The portable Thoratec TLC-II console facilitated discharge while patients waited for a suitable donor heart. (J Thorac Cardiovasc Surg 2010;139:466-73)

Considerable progress has been made during the last 2 decades in the development of ventricular assist devices (VADs). Initially, failure to wean from cardiopulmonary bypass $(\mathrm{CPB})$ was the primary indication for VAD support. ${ }^{1-5}$ The role of VADs then expanded to bridging patients to cardiac transplantation. ${ }^{6-10}$

The Thoratec (Thoratec Corp, Pleasanton, CA) paracorporeal ventricular assist device (PVAD) was the mainstay

\footnotetext{
From the Transplant Unit, Papworth Hospital, Papworth Everard, Cambridge, United Kingdom.

Disclosures: None.

Received for publication March 13, 2009; revisions received June 26, 2009; accepted for publication July 19, 2009; available ahead of print Oct 15, 2009.

Reprint requests: Steven S. L. Tsui, MD, FRCS, Director of Transplant and MCSD, Papworth Hospital, Papworth Everard, Cambridge CB23 3RE, United Kingdom.

(E-mail: steven.tsui@papworth.nhs.uk).

0022-5223/\$36.00

Copyright $\Subset 2010$ published by Elsevier Inc. on behalf of The American Association for Thoracic Surgery

doi:10.1016/j.jtcvs.2009.07.058
}

of many mechanical circulatory support programs with more than 4000 implants in patients worldwide. The newer Thoratec implantable ventricular assist device (IVAD) was designed to have a blood path identical to that of the PVAD system. ${ }^{11,12}$ The IVAD underwent a regulatory trial and was approved in $2004 .{ }^{13}$ This article reports the clinical experience with the Thoratec IVAD as a bridge-to-transplant device in a single institution. Surgical aspects specific to the Thoratec IVAD and potential technical pitfalls are discussed.

\section{PATIENTS AND METHODS}

Clinical records of all patients implanted with the Thoratec IVAD at Papworth Hospital between January 2002 and December 2007 were retrospectively reviewed. This study was approved by the local research ethics committee. Data collected and analyzed include patient medical history, demographics, hemodynamics, blood parameters pre- and post-VAD implantation, adverse events, and outcome. The primary end point was survival to heart transplantation. 

Abbreviations and Acronyms
$\mathrm{BVAD}=$ biventricular assist device
$\mathrm{CPB}=$ cardiopulmonary bypass
$\mathrm{CVVH}=$ continuous venovenous hemofiltration
IVAD $=$ implantable ventricular assist device
LV $=$ left ventricular
LVAD $=$ left ventricular assist device
PVAD $=$ paracorporeal ventricular assist device
$\mathrm{RV}=$ right ventricular
$\mathrm{RVAD}=$ right ventricular assist device
$\mathrm{VAD}=$ ventricular assist device

\section{Surgical Implantation}

All IVADs were implanted through a median sternotomy incision. Generally, the VAD pump pocket was created, and the driveline was pulled through the subcutaneous tunnel before systemic anticoagulation.

\section{Hybrid Pump Pocket}

A median sternotomy incision is extended onto the linea alba for $5 \mathrm{~cm}$. The pre-peritoneal fat is dissected away from the posterior rectus sheath laterally for $3 \mathrm{~cm}$. This forms the medial half of the pump pocket. A longitudinal incision is made along the full length of the posterior rectus sheath approximately $3 \mathrm{~cm}$ lateral to the linea alba. A new dissection plane is then developed laterally between the rectus abdominis muscle and the posterior rectus sheath, continuing deep to the external oblique muscle, providing the lateral half of the "hybrid" pump pocket. The pump pocket extends laterally to the apex of the heart and inferiorly to the level of the iliac crest. The anterior small muscles between the diaphragm and the costal margin are divided between ligatures or surgical clips. The IVAD sizer is used to assess the pump pocket volume, taking care to verify that the tips of the pump caps lie just below the level of the diaphragm.

\section{Two-Staged Double Tunnel for the Driveline}

To facilitate tunneling of the IVAD driveline, a 3 -cm transverse skin incision is made in the lower abdominal wall just below the level of the anterior superior iliac spine. For the final driveline exit site, a separate stab incision is made in the skin at the level of the fifth or sixth rib along the left anterior axillary line. The driveline is first tunneled from the pump pocket caudally through the rectus muscle to the lower abdominal incision. It is then directed back into the wound and tunneled in the subcutaneous tissues cranially toward the stab incision at the chosen driveline exit site (Figure 1). This creates a long tunnel gently curving through 180 degrees at the lower end, increasing the length of the tissue ingrown barrier to infection. The pre-primed IVAD is seated in the pump pocket by caudal traction on the driveline through the lower abdominal incision. The connector for the driveline is assembled after the driveline has been exteriorized. The pneumatic and electrical leads can then be connected and the ends handed out ready for connection to the external drive console. Once the position of the driveline is finalized, the transverse incision on the lower abdominal wall is closed.

\section{Cardiopulmonary Bypass Strategy}

All IVAD implants were conducted using normothermic CPB and fulldose aprotinin. (Since July of 2008, aprotinin is no longer available for use in the United Kingdom.) The lungs were continuously ventilated with tidal volumes of $10 \mathrm{~mL} / \mathrm{kg}$ and 10 parts per million of nitric oxide throughout to prevent atelectasis and to dilate the pulmonary vasculature. Base excess was maintained at $\pm 2 \mathrm{mEq}$, and hemoglobin was maintained at more

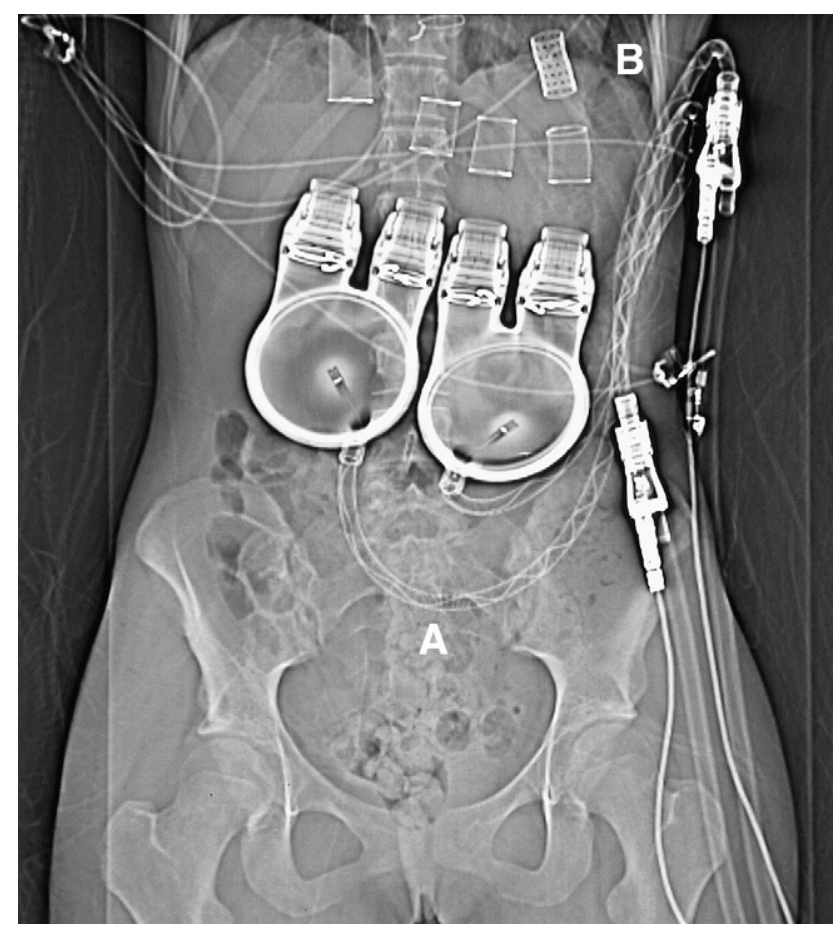

FIGURE 1. Computed tomography scan of a patient with biventricular Thoratec (Thoratec Corp, Pleasanton, Calif) IVAD support illustrating double tunneling of the drivelines and exit in the left lateral chest wall. A, Small transverse skin incision in lower abdomen quadrant. B, Stab incision on lateral chest wall for driveline exit. The driveline is pulled from pump pocket through to A and then taken through a subcutaneous tunnel from A to B.

than $10 \mathrm{~g} / \mathrm{dL}$. The pericardial space is flooded with carbon dioxide at $2 \mathrm{~L} / \mathrm{min}$. No aortic crossclamp or cardioplegia arrest was used.

\section{Implantable Ventricular Assist Device Outflow Cannulation}

The IVAD outflow cannula consists of a curved Thoralon (Thoratec Corp, Pleasanton, Calif) polyurethane tubing and a length of Dacron vascular graft which is pre-clotted with a mixture of blood and fresh-frozen plasma before use. The graft is cut to the correct length and anastomosed end to side to the ascending aorta with a continuous 5-0 Prolene suture.

\section{Implantable Ventricular Assist Device Inflow Cannulation}

The anterior aspect of the left ventricular (LV) apex is exposed and cored, removing approximately $0.5 \mathrm{~cm}$ diameter of myocardium for histology. The ventricular chamber is inspected for mural thrombus and prominent trabeculae, which are removed. The IVAD inflow cannula has a 45-degree curve in its extracardiac segment. The tip of the inflow cannula should be inserted into the left ventricle with the extracardiac part pointing caudally (ie, toward the patient's feet). The sewing ring is secured to the ventricle using 8 horizontal mattress Teflon felt pledgeted 2-0 Ethibond stitches. A silicone membrane is used to minimize adhesions to the pericardium. After returning the apex to the anatomic position, the intraventricular end of the IVAD inflow cannula should be directed at the mitral valve (ie, posteriorly and medially). Care must be taken to maintain this orientation when the extracardiac end of the inflow cannula is attached to the IVAD (Figure 2, $A, B$ ).

The outflow cannula is connected to the IVAD with the curve directed toward the patient's right side. A de-airing cannula is inserted in the vascular graft of the outflow cannula and connected to a cardiotomy sucker. Before 

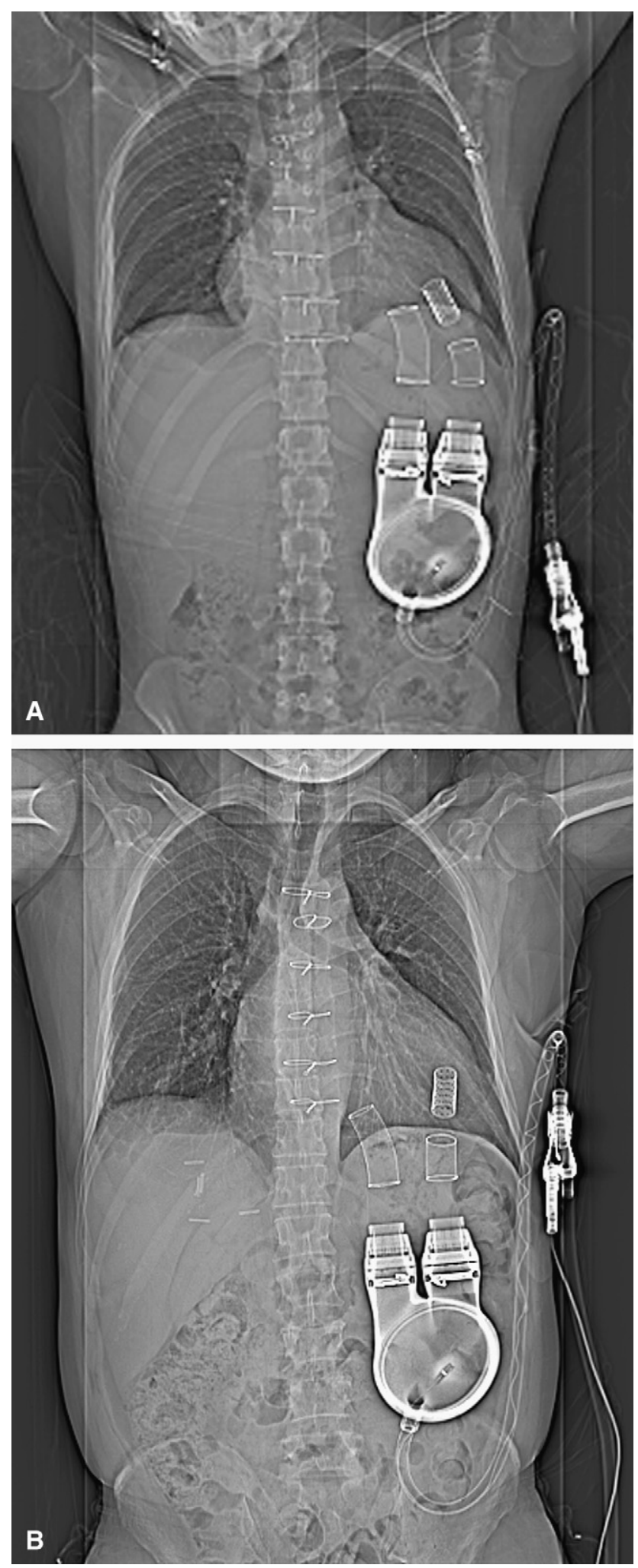

FIGURE 2. Computed tomography scan of 2 Thoratec IVAD recipients. A, Optimal orientation of inflow cannula. B, Malrotation of the inflow cannula. the patient is weaned from $\mathrm{CPB}$, the right ventricle is routinely supported with dopamine at $5 \mu \mathrm{g} / \mathrm{kg} / \mathrm{min}$. The heart is filled to a central venous pressure of $10 \mathrm{~mm} \mathrm{Hg}$, and as the heart begins to eject, bypass flow is reduced. Meticulous de-airing is achieved by slow hand pumping of the IVAD, guided by transesophageal echocardiography. When de-airing is complete, the IVAD driveline is connected to a Thoratec dual drive console, which is set to the automatic mode (fill-to-empty) with initial drive pressure of 80 $\mathrm{mm} \mathrm{Hg}$. The console vent is opened to air; vacuum is not used to assist VAD filling to avoid air entrainment. As filling of the left ventricle improves, the drive pressure is increased stepwise until it is 75 to $100 \mathrm{~mm}$ $\mathrm{Hg}$ above the systolic pressure of the patient to ensure complete emptying of the IVAD. CPB is discontinued, and heparin is fully reversed with protamine sulphate.

The pericardium is closed, either directly or with a strip of silicone sheet. Two intrapericardial drains are placed with further Redivac HVS drains (Medinorm, Spiesen, Germany) in the pump pocket and the retrosternal space. Externally, 2 Hollister Tube Attachment Devices (Hollister Inc, Libertyville, Ill) with cable ties are used to secure the drivelines on the chest wall.

\section{Right Ventricular Assist Device Placement}

If LVAD flows of $2.0 \mathrm{~L} / \mathrm{min} / \mathrm{m}^{2}$ could not be achieved with central venous pressure of less than $16 \mathrm{~mm} \mathrm{Hg}$, early consideration was given to insert a second IVAD as a right ventricular assist device (RVAD).

A hybrid pump pocket is created in the right upper quadrant as described. The RVAD driveline is tunneled to run alongside the LVAD driveline, exiting 2 to $3 \mathrm{~cm}$ lateral to the LVAD driveline exit site (Figure 1). An atrial cannula designed for the IVAD is inserted in the body of the right atrium and secured with two 4-0 Prolene pledgeted pursestring sutures. The outflow graft is pre-clotted, cut to length, and anastomosed end to side to the pulmonary trunk with a continuous 5-0 Prolene suture. In this configuration, the IVAD has to be positioned in the pump pocket back to front so that the VAD inflow is on the righthand side and the outflow is near the midline. As an alternative to right atrial cannulation for RVAD inflow, the right ventricle can be cannulated with a curved IVAD ventricular inflow cannula. De-airing and weaning from CPB are performed as above.

\section{Anticoagulation Management}

Anticoagulation is omitted for the first 24 hours. Heparin infusion is only commenced when pericardial drainage is less than $25 \mathrm{~mL} / \mathrm{h}$ for 3 consecutive hours, aiming for a partial thromboplastin time of 1.5 to 2.0 times of control. Oral warfarin was started after day 5 when patients were able to tolerate oral medication, aiming for an international normalized ratio of 2.0 to 3.0. Heparin infusion is discontinued when international normalized ratio is greater than 2.0. Antiplatelet agents were not routinely used. Aspirin at 150 $\mathrm{mg}$ once daily was only introduced for patients who experienced transient ischemic attacks despite adequate anticoagulation.

\section{Device Choice}

The choice of device has obviously evolved over time as new devices become available. More recently, the majority of patients received continuous flow devices either as a bridge to transplant (VentrAssist; Ventracor Ltd, Chatswood, Australia) or bridge to decision (Levitronix CentriMag; Levitronix, Waltham, Mass). However, for patients in whom there is a concern that biventricular support might be required, especially those with intractable ventricular arrhythmia or established end-organ failure, the use of Thoratec VADs is favored. In this latter group of patients, those who are stable enough to tolerate pump pocket dissection before CPB would receive the Thoratec IVAD; for patients who are hemodynamically unstable and required early institution of $\mathrm{CPB}$, the Thoratec PVAD would be used.

\section{Analysis}

Data are expressed as mean \pm standard deviation. Data were analyzed univariately by unpaired student $t$ test for continuous variables and by 
chi-square or Fisher's exact test for categoric variables between the groups using a commercially available statistics package: Statview (ver5.0, SAS Institute Inc, Cary, NC).

\section{RESULTS}

\section{Baseline Demographics}

Between January 2002 and December 2007, 99 patients were implanted with VADs: 29 Levitronix CentriMags, 12 Impellas (Abiomed, Aachen, Germany), 24 IVADs, 20 PVADs, 4 HeartMate XVEs (Thoratec Corp), and 10 VentrAssists (Ventracor Ltd).

Of the 24 patients who were implanted with the Thoratec IVAD as a bridge to transplant, $19(79.1 \%)$ received 1 IVAD as a left ventricular assist device (LVAD) and 5 $(21.9 \%)$ received 2 IVADs as biventricular assist devices (BVADs) (Tables 1 and 2). There were 20 male and 4 female patients with a mean age of 39.8 years (17-57 years) and a body surface area of $1.87 \mathrm{~m}^{2}\left(1.63-2.2 \mathrm{~m}^{2}\right)$. Underlying disease was idiopathic dilated cardiomyopathy in 17 patients, ischemic cardiomyopathy in 6 patients, and dilated cardiomyopathy associated with Becker muscular dystrophy in 1 patient. Preoperatively, 23 patients were receiving inotropic support, 12 patients required intra-aortic balloon pump, 3 patients were receiving continuous venovenous hemofiltration $(\mathrm{CVVH})$, and 5 patients were intubated and mechanically ventilated for pulmonary edema.

\section{Outcome and Duration of Support}

Support to transplantation was achieved in 17 patients (70.8\%): 14 of 19 LVADs (73.7\%) and 3 of 5 BVADs $(60 \%)$ (Figure $3, A)$. Cumulative IVAD support duration for the whole group was 2308 patient-days (6.48 patientyears), with an average support time of 96 days (10-301 days). For those successfully bridged to transplant, the mean duration of support was 106 days (10-301 days); for those who died on support, the mean duration of support was 57 days (12-154 days). Eleven patients $(45.8 \%)$ were discharged with VAD support using the portable Thoratec TLC- II driver and remained at home for a total of 1015

TABLE 1. Patient clinical status

\begin{tabular}{lc}
\hline \multicolumn{1}{c}{ Parameter } & Mean $( \pm$ SD $)$ \\
\hline Age $(\mathrm{y})$ & $39.4( \pm 13.6)$ \\
Pre-VAD CI $\left(\mathrm{L} / \mathrm{min} / \mathrm{m}^{2}\right)$ & $1.67( \pm 0.5)$ \\
Pre-VAD CVP $(\mathrm{mm} \mathrm{Hg})$ & $17.9( \pm 7.2)$ \\
Pre-VAD mPA $(\mathrm{mm} \mathrm{Hg})$ & $35.2( \pm 10.1)$ \\
Pre-VAD PCWP $(\mathrm{mm} \mathrm{Hg})$ & $27.5( \pm 5.9)$ \\
Pre-VAD creatinine $(\mu \mathrm{mol} / \mathrm{L})$ & $114.2( \pm 29.5)$ \\
Pre-VAD bilirubin $(\mu \mathrm{mol} / \mathrm{L})$ & $44.1( \pm 24.9)$ \\
Pre-VAD albumin $(\mathrm{g} / \mathrm{L})$ & $29( \pm 5.3)$ \\
Pre-VAD ALT $(\mathrm{U} / \mathrm{L})$ & $275( \pm 81)$ \\
\hline
\end{tabular}

$A L T$, Alanine aminotransferase; $C I$, cardiac index; $C V P$, central venous pressure; $P A$, pulmonary artery; $I A B P$, intraaortic balloon pump; $C V V H$, continuous venovenous hemofiltration; $V A D$, ventricular assist device; $m P A$, main pulmonary artery; $P C W P$, pulmonary capillary wedge pressure; $S D$, standard deviation.
TABLE 2. Patient pre-implant support

\begin{tabular}{lc}
\hline \multicolumn{1}{c}{ Parameter } & $\mathbf{N}(\%)$ \\
\hline Other organ failing & $8(33 \%)$ \\
Pre-VAD IABP & $12(50 \%)$ \\
Pre-VAD CVVH & $3(12.5 \%)$ \\
Pre-VAD ventilation & $5(20.8 \%)$ \\
\hline$V A D$, Ventricular assist device; $I A B P$, intraaortic balloon pump; $C V V H$, continuous \\
venovenous hemofiltration.
\end{tabular}

home patient-days (2.78 patient-years) (Figure $3, B$ ). Of the 13 patients who were not discharged, 4 died in the intensive care unit, 3 died on the ward, and 6 were bridged to heart transplant. Those who died in hospital had adverse events and were never well enough to consider hospital discharge. The reasons for non-discharge in those who underwent transplantation were as follows: a suitable donor heart became available very soon after the patients were fit for transplant $(\mathrm{n}=3)$ and a lack of social/family support at home precluding home discharge until after heart transplant $(n=3)$.

\section{Adverse Events}

The majority of adverse events occurred within 30 days of VAD implantation, and mostly while the patients were still in hospital.

\section{Bleeding}

Six patients underwent re-sternotomy for bleeding, mostly for cardiac tamponade within the first few days of VAD implant. Of these 6 patients, only 2 survived to transplantation. A hemothorax developed in 1 patient after a central venous line exchange, requiring a thoracotomy to control the bleeding.

\section{Cannula Malposition}

One patient had persistently poor LVAD flow early after LVAD insertion. This was associated with high pulmonary capillary wedge pressure and a full left ventricle on echocardiography. The problem was due to the IVAD being placed in too small a pump pocket and the inflow cannula wrongly pointing toward the lateral wall of the left ventricle. This patient required revision surgery to shorten and rotate the inflow cannula to improve LV drainage.

\section{Right Ventricular Failure}

Late right ventricular (RV) failure developed in 2 of the 19 patients receiving LVADs, requiring temporary RVAD support with the Levitronix Centrimag $(10.5 \%)$. The first of these patients was initially reexplored for tamponade on day 8 post-LVAD. Despite decompressing the heart, RV function remained poor with inadequate LVAD filling. A temporary RVAD was therefore inserted. Acute onset of abdominal pain developed in the second patient 10 days post-LVAD and metabolic acidosis, requiring an emergency laparotomy and hemicolectomy for ischemic bowel. His 


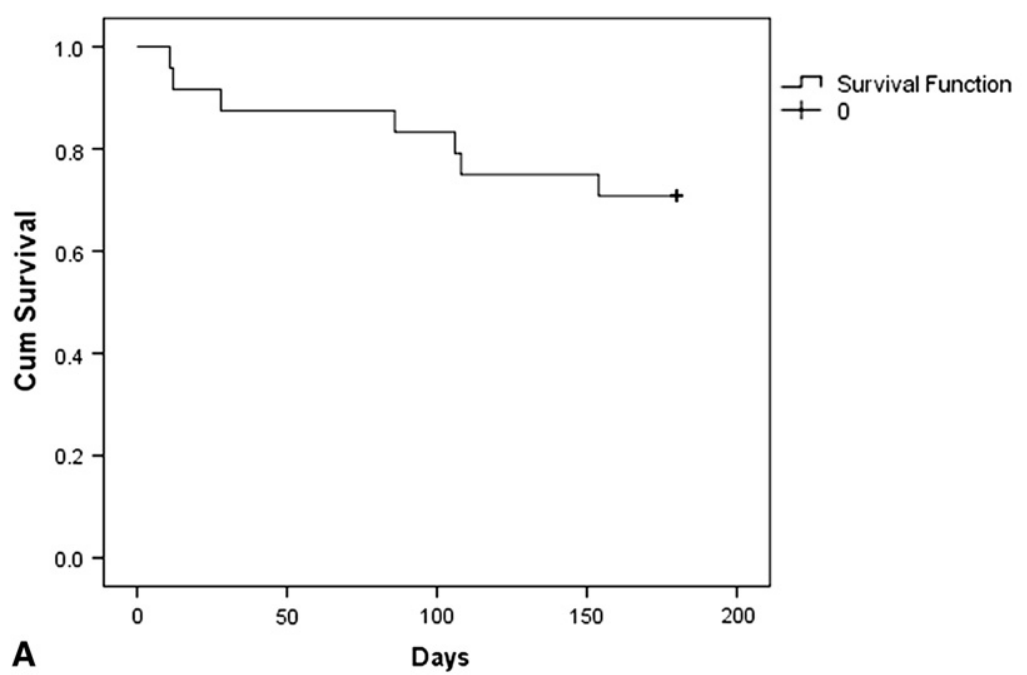

IVAD Thoratec support days distribution

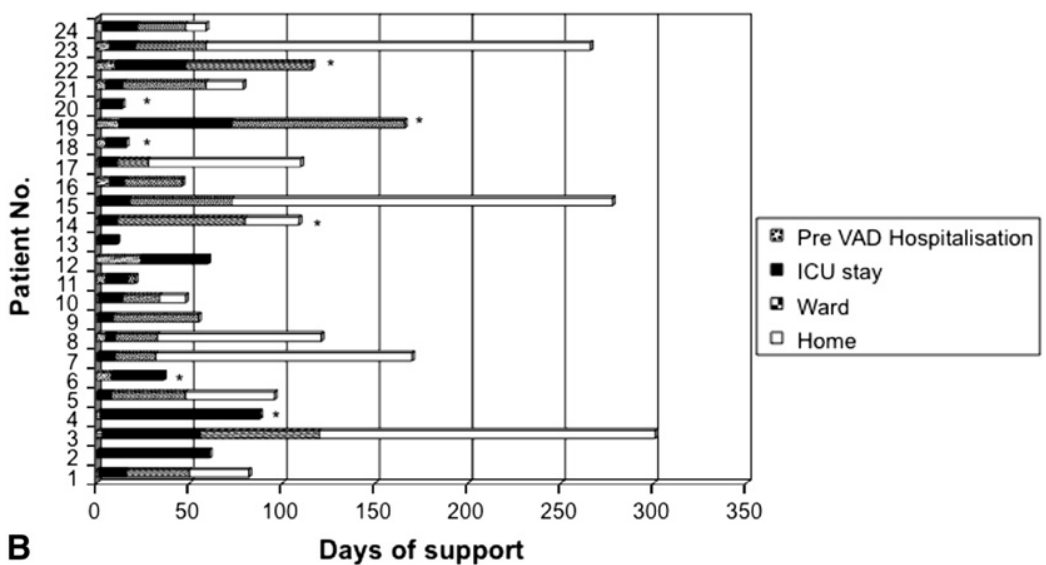

FIGURE 3. A, Actuarial 6-month survival: underwent heart transplant or remain on VAD support and eligible for transplantation. B, Individual patient detailed VAD support time, including the preoperative and postoperative hospitalization period and home support. *Patients died while being VAD supported. The remaining patients were bridged to transplant.

condition remained poor after the laparotomy and RV function gradually deteriorated, requiring RVAD insertion the following day. Despite biventricular support, both patients subsequently died of multiorgan system failure.

\section{Infection}

Driveline infection occurred in 3 patients $(0.47$ driveline infections/patient-year of support). All responded well to antibiotic treatment, and none went on to develop pump pocket infection. Pump pocket infection refractory to medical treatment developed in 1 patient. He eventually died of sepsis.

\section{Neurologic Complications}

Three of the 24 patients had a stroke ( 0.47 strokes/patientyear of support). One patient had a spontaneous intracranial hemorrhage on day 95 post-LVAD that was fatal. Two patients had computed tomography-proven cerebral emboli: One made a complete recovery and underwent successful transplantation, and one died on support. Four other patients had 6 episodes of transient ischemic attacks ( 0.94 transient ischemic attack/patient-year of support). All of them recovered and were successfully bridged to transplant. At the time of these neurologic events, all patients had international normalized ratios that were within therapeutic range.

\section{Renal Failure}

Severe renal dysfunction occurred in 9 patients $(37.5 \%)$, who required CVVH. Four patients recovered and underwent successful heart transplant; the other 5 patients died while on VAD support.

\section{Abdominal Complications}

Two patients had abdominal complications; one required a left hemicolectomy for bowel ischemia 10 days postLVAD placement (see above), and one had clinical 
appendicitis (supported by laboratory and computed tomography findings) and underwent successful appendectomy.

\section{Mechanical Device Failure}

There was no mechanical failure of the IVAD, and no IVAD required replacement. One patient experienced battery malfunction with the TLC-II driver failing to switch between the 2 batteries. He simply swapped over to a backup driver, which is supplied to all patients.

\section{DISCUSSION}

The Thoratec IVAD is the only implantable VAD that can be used for uni- or biventricular support. In the present series, $79 \%$ of patients required 1 IVAD as LVAD and $21 \%$ of patients required 2 IVADs as biventricular support from the outset. Among the patients receiving an LVAD, 11\% subsequently required late RVAD support. The overall survival for the whole series was $70.8 \%$. Of those who only required LVAD, $82.4 \%$ were successfully bridged to transplant (14/17 patients). Those requiring BVAD support from the outset had a slightly lower survival of $60 \%$ (3/5). For the 2 patients receiving an LVAD who required late RVAD support, mortality was $100 \%$. This confirmed that when required, early insertion of RVAD at the time of LVAD implantation provides superior outcome. These results are consistent with the international multicenter study of the Thoratec IVAD (Table 3). ${ }^{13}$

In this series, the smallest patients with a BVAD implanted with 2 Thoratec IVADs was a 17-year-old female weighing $47 \mathrm{~kg}$ with a body surface area of $1.63 \mathrm{~m}^{2}$. She was discharged home on VAD support and was successfully bridged to transplant after 301 days.

Although the design of the Thoratec IVAD is similar to its predecessor, the IVAD is aesthetically more acceptable to patients and caregivers by being intracorporeal. The single flexible IVAD driveline is easier to manage than the 2 large percutaneous inflow and outflow cannulae of the PVAD. In addition, the implanted IVAD has an optical sensor to assess pump emptying and does not require regular visual checks with the "flash test", as with the PVAD. Furthermore, by being implanted inside the abdominal wall, improvised slings that are necessary to carry the PVAD are no longer required. These factors all contribute to a higher discharge rate of $46 \%$ in our IVAD series when compared with our PVAD experience. The single flexible percutaneous driveline of the IVAD also contributes to a lower exit site infection rate when compared with that of the double exit sites of the larger PVAD cannulae: infection rate of 0.32 (IVAD) versus 0.61 (PVAD) with a risk ratio of $0.53 .^{13}$ This probably contributed to the relatively low rate of deep-seated infections in this IVAD series.

$\mathrm{RV}$ failure remains a serious potential complication of LVAD implantation. Treatment of RV failure post-LVAD implantation includes the use of inotropic support, pulmo-
TABLE 3. Descriptive outcome comparison between the Papworth Hospital implantable ventricular assist device experience and the multicenter implantable ventricular assist device Thoratec study ${ }^{15}$

\begin{tabular}{|c|c|c|}
\hline & $\begin{array}{l}\text { Papworth series } \\
\quad(\mathbf{n}=\mathbf{2 4})\end{array}$ & $\begin{array}{l}\text { Multicenter study } \\
\qquad(\mathbf{n}=\mathbf{3 9})\end{array}$ \\
\hline Indications & $\begin{array}{c}\text { All BTTDCM }= \\
18 \mathrm{IHD}=6\end{array}$ & $\mathrm{BTT}=30 \mathrm{PC}=9$ \\
\hline $\begin{array}{l}\text { Mean duration of } \\
\text { support (d) }\end{array}$ & BTT $96(10-301)$ & $\begin{array}{c}\text { BTT } 108(9-597) \text { PC } \\
77(14-250)\end{array}$ \\
\hline $\begin{array}{l}\text { Total duration of } \\
\text { support }\end{array}$ & $\begin{array}{l}2305 \text { patient-d (6.31 } \\
\text { patient-y) }\end{array}$ & $\begin{array}{l}3938 \text { patient-d (10.8 } \\
\text { patient-y) }\end{array}$ \\
\hline $\begin{array}{l}\text { Home discharge } \\
\text { (patients) }\end{array}$ & $\begin{array}{l}\text { 11/24 (45.8\%) } 1015 \\
\text { patient-d }\end{array}$ & $\begin{array}{l}18 / 39(46.1 \%) \text { Not } \\
\text { available }\end{array}$ \\
\hline $\begin{array}{c}\text { Success rate of } \\
\text { BTT/BTR }\end{array}$ & $17 / 24(70.8 \%)$ & $27 / 39(69.2 \%)$ \\
\hline LVAD & $14 / 19(73.7 \%)$ & $19 / 24(79.1 \%)$ \\
\hline BVAD & $3 / 5(60 \%)$ & $8 / 15(53.3 \%)$ \\
\hline Readmission & $\begin{array}{l}7 \text { patients with } 9 \\
\text { episodes }\end{array}$ & $\begin{array}{l}10 \text { patients with } 15 \\
\text { episodes }\end{array}$ \\
\hline \multicolumn{3}{|l|}{ Neurologic } \\
\hline CVA & $3 / 24(12.5 \%)$ & $3 / 39(7.7 \%)$ \\
\hline TIA & 0.94 patient-y & 1.94 patient-y \\
\hline \multicolumn{3}{|l|}{ Infection } \\
\hline Pocket & $1 / 24$ & $2 / 39$ \\
\hline Drive line & $3 / 24(12.5 \%)$ & $5 / 39(12.8 \%)$ \\
\hline
\end{tabular}

$B T T$, Bridge to transplant; $C V A$, cerebral vascular accident; $D C M$, dilated cardiomyopathy; $I H D$, ischemic heart disease; $P C$, postcardiotomy failure; $T I A$, transient ischemic attack. Twelve patients from the Papworth group who received an IVAD before June 2004 were included in the multicenter study.

nary vasodilatation, or RVAD support. We believe it is important to prevent the increase in pulmonary vascular resistance and minimize RV injury during LVAD implantation. The use of nitric oxide preemptively for all patients forms part of our routine RV protection strategy. ${ }^{14,15}$ However, nitric oxide is routinely weaned within 12 to 24 hours post-VAD implant, and when necessary, substituted with nebulized iloprost 3-9 $\mu \mathrm{g}$ every 3 hours, with the dose adjusted according to response.

The number of patients requiring CVVH post-VAD included 3 patients who required CVVH pre-VAD. Two of 5 patients with BiVADs required CVVH post-implant, and 1 patient died of multiorgan system failure.

We think it is important to minimize the central venous pressure in patients with VADs, particularly in those with preexisting end-organ dysfunction. As a result, instead of relying on diuretic therapy alone, we have a low threshold for using CVVH to optimize volume status. This explains the high rate of CVVH use in our patients with VADs postoperatively. Use of CVVH does not indicate renal failure. ${ }^{16}$

There are special technical considerations when implanting the Thoratec IVAD. Although the dimensions of the Thoratec IVAD are significantly smaller than those of other implantable pulsatile devices, the abdominal pump pocket required to accommodate the IVAD is still considerable, particularly in its vertical dimension. This is to accommodate the 
length of the extracardiac portion of the IVAD inflow cannula and the connector/inflow valve housing on the IVAD. Failure to dissect a deep enough pump pocket may cause the IVAD to ride high, distorting the LV apex, with the risk of compromising LVAD filling. For this reason, we prefer to use the shortest available inflow cannula to reduce the size of the required pump pocket. The hybrid pump pocket takes advantage of the distensible pre-peritoneal space medially and the resilience of the posterior rectus sheath laterally.

The curve in the IVAD inflow cannula is designed to align the mouth of the inflow with the long axis of the left ventricle, thereby improving LV drainage. However, it also introduces potential technical pitfalls. For the left ventricle to drain freely into the IVAD, the ventricular opening of the inflow cannula must be directed toward the mitral valve opening, that is, with a 30 - to 40 -degree rotation posteromedially. If the inflow cannula is inadvertently connected to the IVAD with a 90-degree rotation instead, the opening of the inflow cannula would face the posterior LV endocardium, leading to poor drainage of the left ventricle and poor LVAD flows. If the mouth of the inflow cannula points laterally, the situation is even worse. This occurred with one of our earlier IVAD implants. Once this situation was recognized, that patient was returned to the operation room for re-sternotomy and revision of the inflow cannula orientation. Fortunately, it was possible to accomplish this revision without putting the patient back on CPB.

The Thoratec IVAD outflow cannula is a composite between a Thoralon tube (a Thoratec proprietary polyurethane) and a Dacron vascular graft. When connecting this outflow cannula to the IVAD, the curve should point squarely toward the right of the patient, directing the Dacron graft into a gentle curve toward the right anterolateral surface of the ascending aorta (Figure 2).

The result from this series confirms that the Thoratec IVAD is a reliable device for bridging patients to heart transplantation. There was no mechanical failure, allowing major organ function recovery. The $71 \%$ successful bridge to transplant rate in this series is similar to that reported previously in the Thoratec IVAD multicenter trial $(69 \%) .{ }^{13}$ It is also comparable to the success rate reported with other pulsatile devices, such as the Thoratec PVAD $(65 \%){ }^{17}$ the HeartMate IP LVAD $(71 \%),{ }^{6}$ and the HeartMate VE (LVAS, $71 \%$ ). In this series, patients who required biventricular support at the time of LVAD implant had a lower survival $(60 \%)$, consistent with previous studies demonstrating that patients with increased severity of illness, especially with renal and hepatic failure, are more likely to require BVADs and thus be at a higher risk of death than patients requiring LVAD alone. However, patients implanted with an RVAD at the time of LVAD insertion still fared better than those who had late insertion of RVAD. All adverse events recorded in this study are commonly en- countered with other implantable VAD. The incidences are also consistent with those reported previously. ${ }^{12,13}$

During the study period, our indications for BIVAD were a) intractable ventricular arrhythmia and b) LVAD flow less than $2.0 \mathrm{~L} / \mathrm{min} / \mathrm{m}^{2}$ or right atrial pressure more than $20 \mathrm{~mm}$ Hg. ${ }^{18}$

More recently, we have lowered our threshold for deploying RVAD and adjusted our indications to include mixed venous oxygen saturation less than $60 \%$ with right atrial pressure greater than $16 \mathrm{~mm} \mathrm{Hg}$.

There has been tremendous progress in the field of mechanical circulatory support during the last 5 years. Recent results of new rotary LVADs such as the HeartMate II and the VentrAssist have been excellent. ${ }^{19,20}$ These smaller devices have now become the first choice for most patients requiring LVAD support. However, in the decompensated patients who are unable to undergo transplantation because of acute end-organ failure, the chances of requiring BVAD support remains significant, and we continue to select the Thoratec IVAD in those cases. Other patients in whom we would preferentially use the IVAD include those with intractable ventricular arrhythmias and those with significant or predominant RV failure.

\section{CONCLUSIONS}

The Thoratec IVAD has demonstrated the capability of providing univentricular and biventricular support, with an acceptable complication rate. Extended cardiac support was provided for as long as 301 days, and approximately half of the patients were successfully discharged to await cardiac transplantation.

The authors acknowledge the contribution of Carol Freeman, research officer, Papworth Hospital, United Kingdom.

\section{References}

1. DeBakey ME. Left ventricular bypass pump for cardiac assistance: clinical experience. Am J Cardiol. 1971;27:3-11.

2. Litwak RS, Koffsky RM, Jurado RA, Lukban SB, Ortiz AF, Fischer AP. Use of a left heart assist device after intracardiac surgery: technique and clinical experience. Ann Thorac Surg. 1976;21:191-202.

3. Norman JC, Duncan JM, Frazier OH, Hallman GL, Ott DA, Reul GJ. Intracorporeal (abdominal) left ventricular assist devices or partial artificial hearts: a five-year clinical experience. Arch Surg. 1981;116:1441-5.

4. Pennington DG, Merjavy JP, Swartz MT, Codd JE, Barner HB, Lagunoff D. The importance of biventricular failure in patients with postoperative cardiogenic shock. Ann Thorac Surg. 1985;3:170-8.

5. Korfer R, el-Banayosy A, Posival H, Minami K, Korner MM, Arusoglu L. Mechanical circulatory support: the Bad Oeynhausen experience. Ann Thorac Surg. 1995;59:S56-63.

6. Frazier OH, Rose EA, McCarthy P, Burton NA, Tector A, Levin H. Improved mortality and rehabilitation of transplant candidates treated with a long-term implantable left ventricular assist system. Ann Surg. 1995;222:327-38.

7. Farrar DJ, Hill JD, Pennington DG, McBride LR, Holman WL, Kormos RL. Preoperative and postoperative comparison of patients with univentricular and biventricular support with the Thoratec ventricular assist device as a bridge to cardiac transplantation. J Thorac Cardiovasc Surg. 1997;113:202-9.

8. McBride LR, Naunheim KS, Fiore AC, Moroney DA, Swartz MT. Clinical experience with 111 Thoratec ventricular assist devices. Ann Thorac Surg. 1999;67: 1233-9. 
9. Morgan JA, John R, Rao V, Weinberg AD, Lee BJ, Mazzeo PA. Bridging to transplant with the HeartMate left ventricular assist device: the Columbia Presbyterian 12-year experience. J Thorac Cardiovasc Surg. 2004;127:1309-16.

10. Copeland JG, Smith RG, Arabia FA, Nolan PE, Sethi GK, Tsau PH. Cardiac replacement with a total artificial heart as a bridge to transplantation. N Engl J Med. 2004;351:859-67.

11. Samuels LE, Holmes EC, Hagan K, Gopalan R, Droogan C, Ferdinand F. The Thoratec implantable ventricular device (IVAD): initial clinical experience. Heart Surg Forum. 2006;9:E690-2.

12. Reichenbach SH, Farrar DJ, Hill JD. A versatile intracorporeal assist device based on the Thoratec VAD system. Ann Thorac Surg. 2001;71:S171-5.

13. Slaughter MS, Tsui SS, El-Banayosy A, Sun BC, Kormos RL, Mueller DK, et al., and IVAD Study Group. Results of a multicenter clinical trial with the Thoratec implantable ventricular assist device. J Thorac Cardiovasc Surg. 2007;133: 1573-80.

14. Argenziano M, Choudri AF, Moazami N, Rose EA, Smith CR, Levin HR, et al. Randomized, double-blind trial of inhaled nitric oxide in LVAD recipients with pulmonary hypertension. Ann Thorac Surg. 1998;65:340-5.
15. Tsui S, Parameshawar J. Shock Due to Catastrophic Loss of Myocardium. Philadelphia: Elsevier; ISHLT monograph series, volume 3, part 2. 2008:509-23.

16. Tsui S, Parameshwar J. Mechanical circulatory support. In: Klein A, Vuylsteke A Nashef S, eds. Core topics in cardiothoracic critical care. New York: Cambridge University Press; 2008:159-68.

17. Kirsh M, Vermes E, Radu C, Streich B, Nakashima K, Mekontso-Dessap A, et al. Impact of preoperative hemodynamic support on early outcome in patients assisted with paracorporeal Thoratec ventricular assist device. Eur J Cardiothorac Surg. 2008;34:262-7.

18. Chen JM, Rose EA. Management of right sided circulatory failure. In: Godstein DJ, Oz MC, eds. Cardiac Assist Devices. Armonk, NY: Future Publishing; 2000:83-101.

19. Miller LW, Pagani FD, Russell SD, John R, Boyle AJ, Aaronson KD, et al. HeartMate II Clinical Investigators. Use of continuous flow device in patients awaiting heart transplantation. $N$ Engl J Med. 2007;357:885-96.

20. Esmore D, Kaye D, Spratt P, Larbalestier R, Ruygrok P, Tsui S, et al. A prospective, multicenter trial for VentrAssist left ventricular assist device for bridge to transplant: safety and efficacy. J Heart Lung Transplant. 2008;27:579-88. 